\title{
Andrea Carrión y María Fernanda López-Sandoval (coords.) (2021). Ciudades intermediasy nueva ruralidad. 356 págs. Quito: FLACSO Ecuador. ISBN: 9789978675496.
}

Los acelerados procesos de urbanización que se han vivido durante las últimas décadas en América Latina han configurado un paisaje urbano complejo con metrópolis gigantescas y el surgimiento de ciudades intermedias que luchan por ser sostenibles. El debate entre lo urbano y rural se ha acrecentado aún más a raíz de la pandemia que atraviesa el planeta, en términos de políticas públicas, gobernanza y aplicación de la Agenda 2030. Sin embargo, una de las virtudes de esta obra es el abordaje íntegro a la cuestión de los asentamientos humanos trascendiendo la yuxtaposición urbano-rural. Y el marco para esta discusión viene de la alianza entre la Asociación Geográfica del Ecuador (AGEC) y la Facultad Latinoamericana de Ciencias Sociales -FLACSO-Ecuador. Esta última, durante los postreros cuatro años, ha venido desarrollando una línea de investigación centrada en los cambios de las distribuciones geográficas en el ámbito rural ecuatoriano de las pasadas tres décadas. De este modo, el objeto de estudio ha remarcado el especial interés que existe en el Ecuador entre lo rural y lo urbano desde un abordaje integral. Más aún teniendo en cuenta que en octubre de 2019 las protestas y movilizaciones sociales que acontecieron por todo el país pusieron en jaque las cadenas de suministros de primera necesidad de las áreas rurales hacia las ciudades con el corte de las carreteras durante varios días, llegando a amenazar con el desabastecimiento de productos del campo a ciudades intermedias como Cuenca. Por último, en la preparación de las discusiones previas a la elaboración de esta investigación, intervino la Cooperación Técnica Alemana (GIZ), dentro de su programa de ciudades intermedias sostenibles.

En cuanto a la organización del libro, se estructura en tres partes con una metodología de estudio de casos a nivel de la región. La primera de ellas está dedicada a la reflexión que conlleva el desarrollo de ciudades intermedias, en contraposición a los modelos urbanos que dan preferencia a las ciudades capitales de cada país, cuestionando los modelos de expansión heredados de varias décadas bajo el esquema de megalópolis, predominante en Brasil, México y Argentina. Varias preguntas guían este apartado, como cuál es el escenario de las ciudades intermedias dentro de cada realidad nacional referente a políticas públicas tales como desarrollo sostenible y económico, ambientales, etc. Asimismo, si existen fórmulas de interrelación entre estas ciudades intermedias y otros niveles superiores de gobierno, y qué políticas públicas (nacionales o seccionales) se aplican para incentivar o desincentivar la concentración poblacional en estas ciudades. Los casos que desarrollan las preguntas anteriores están enfocados en las ciudades intermedias argentinas y sus planes de ordenamiento territorial; el papel de estas en el estado brasileño de Rio Grande do Sul, y la evolución demográfica en los frentes marítimos, lacustres y fluviales de Chile.

A continuación, se analizan las interacciones entre las ciudades intermedias y su ámbito rural. Algunas de las cuestiones que orientan los casos analizados tienen que ver con los patrones que reproducen las ciudades intermedias en su expansión territorial tales como segregación y marginalidad, a semejanza de las grandes urbes. Países con un fuerte componente rural como Ecuador y Colombia, pero también otros como México y Chile, presentan sus experiencias con énfasis en la producción agrícola y los modelos de ordenamiento territorial que pudieran estar empeorando un crecimiento urbano y sociodemográfico sostenible. 
El tercer bloque temático estudia el vínculo entre grandes ciudades y ciudades intermedias. Específicamente su correlación con las áreas rurales y cómo en un contexto de políticas neoliberales se afecta el tejido agroproductivo de estas zonas. Aquí entran en juego nuevas percepciones, resistencia al cambio (urbano), reforzamiento de identidades rurales y un nuevo papel de la naturaleza y el agro como sujeto de derechos, como el caso de Ecuador. En resumen, el posicionamiento de lo rural frente a la globalización urbana que se presenta tan irresistible en la actualidad. Se exponen casos de Marabá y Mata Norte Pernambucana en Brasil, la región del Chocó Andino en Ecuador, las ciudades intermedias del subtrópico mexicano y la ciudad turística de Girardot en Colombia frente al desarrollo de su área rural.

En conclusión, el abordaje multidisciplinar de la obra, su amplitud y minuciosidad en el estudio de casos, así como que la temática abordada siempre está presente en la realidad de la región, hacen de su lectura el punto de partida para otras investigaciones en distintas disciplinas.

David MOLINA ROMO

Universidad de Salamanca 